\title{
Apuntes desde la semiótica: hacia una antropófaga comunicación intercultural
}

RODRIGO BROWNE SARTORI Universidad Austral de Chile 


\section{Resumen}

El propósito del presente trabajo es romper, desde un giro semióticointercultural, con la lógica tradicional. Una lógica que construye imaginarios a partir de lecturas sesgadas provenientes de los discursos de autoridad. Como reacción a este quiebre se intenta potenciar un proyecto deconstructivo que brota de la carga negativa generada en torno a nociones como la antropofagia. Concepto que, en el diccionario de la $R A E$, se define como perverso y antioccidental. Para resistir al hermetismo de dicho discurso se reivindican las estrategias de subversión que habilita el manifesto antropofago (1928) de Oswald de Andrade; ejercicio que permite estimular una mirada antropófaga de y hacia la comunicación intercultural.

\section{Palabras-chave}

comunicación intercultural, antropofagia, Oswald de Andrade

\section{Abstract}

The purpose of the following paper is to break up-from an interculturalsemiotic focus- the traditional logic. A logic which constructs imaginaries drawn from biased readings based upon the discourses of the authority. As a reaction to that breaking it is intended to promote a deconstructive project. A change in the episteme which explodes as a consequence of the negative burden generated in relation to notions as the anthropophagy that, in the R.A.E. dictionary, is defined as evil and anti-occidental. In order to resist the inscrutability of the discourse already mentioned, subversion strategies -enabled by the manifesto antropofago (1928) by Oswald de Andrade- are vindicated; an exercise that allows to stimulate an anthropophagous view from and towards the intercultural communication.

\section{Key words}

intercultural communication, anthropophagy, Oswald de Andrade 
Somos todo el pasado, somos nuestra sangre, somos la gente que hemos visto morir, somos los libros que nos han mejorado, somos gratamente los otros. J.L. Borges, 1979, p.997

7. T Tha de las declaraciones de principios más radicales de la ; vanguardia artístico-cultural latinoamericana fue el Manifesto Antropófago que publicó Oswald de Andrade (1890-1954); en mayo de 1928 y cuyo propósito era clamar por una mirada contracolonial de la antropofagia brasileña como punto de. deglución de, en su cas,o, la parțe más sabrosa de la cultura europea para hacerla carne propia, como un mestizaje de lo cosmopolita y lo local, frente al simbólico acto caníbal de la colonización: "Sin nosotros -escribía de Andrade- Europa ni siquiera tendría su pobre declaración de los derechos del hombre". (Andrade, 1928, p:-3):

Los postulados de. Oswald de Andrade son vitales para introducir lo que se pretende proponer en esta comunicación. La antropofagia como fuente de denuncia de una sociedad patriarcal subsumida por un discurso occidental que embarga lo ajeno y lo exótico...Dicho tema es, sin duda, el principal requerimiento que este artista: $y$ : su apetitoso movimiento aspiró defender y difundir. Por lo mismo, al comenzar su manifiesto, de Andrade no escatimó en indicar que ese punto de reflexión antropófago es lo que pérmite analizar, desde^el placer de la alimentación y las conclusiones de la digestión, el êstado de marginalidad de la cultura brasileña (por ende latinoamericana) y que se manifiesta en la relegación, por parte de los absolutismos imperantes, de las culturas y movimientos periféricós. "Sólo la antropofagia nos une. Socialmente: Económicamente. 
Filosóficamente (...) Tupy, or not tupy that is the question"1 (Andrade, 1928, p. 3), señala Andrade en su manifiesto antropófago.

Desde esta mirada específica, elaboramos un proyecto de análisis del imaginario de las sociedades posmodernas, especialmente en lo que respecta a la cuestión del Otro excluido por una sociedad moderna. Exclusión controlada por un discurso de autoridad que se encerró en un modelo ideal y que obvió todo tipo de marginalidades y opciones alternativas que quedaban, sin más, dejadas en el limbo de lo irracional, lo inconveniente o lo ilegal.

Umberto Eco (2002) en un discurso pronunciado, recientemente, en Jerusalén con motivo del doctorado honoris causa concedido por la Universidad Hebrea, señaló que los siglos anteriores, incluyendo los modernos, han sido escenario de lo que conocemos como colonialismo, racismo, intolerancia, etcétera. En occidente, la responsabilidad del hombre blanco era considerar su civilización (occidental y cristiana) como la única posible, "(...) de aquí -afirma Eco-'el derecho y la misión de convertir a todos aquellos que seguían un modelo cultural diferente" (Eco, 2002, p. 11). Como también -anuncia este intelectual- el surgimiento de actitudes similares en el mundo no occidental, inspiradas por el odio a lo europeo y a su modelo eurocentrista. A continuación, citamos algunas palabras que el mismo Eco pronunció en su discurso:

Mientras que los antropólogos nos han enseñado a reconocer y respetar distintos comportamientos culturales, distintas religiones y costumbres étnicas (...) los primeros medios de comunicación, desde las novelas populares hasta las peliculas de Hollywood, alentaban

1 Los antropófagos que obtuvieron mayor popularidad en Europa fueron los que se encontraron en los actuales territorios de Brasil, Paraguay, Uruguay, Argentina y Bolivia y quienes bajo el nombre de Tupi-Guaraní (de ahí el juego 'Tupy, or not tupy...') -"con leves variantes en las ceremonias; en la forma de ejecutar a la víctima expiatoria, todos los sectores de la gran familia tupi-guaraní cumplian el rito canibal" (Villalta, 1970, p. 75)- se distribuían en diferentes tribus entre las que destaca por su hambrienta ferocidad, según los diversos relatos de los viajeros de la epoca, Los Tupinambas. 
una visión del Otro como un malvado, los feroces indios, el negro estúpido obligado a un destino de eterna esclavitud por su irremediable inferioridad... (Eco, 2002 p. 11)

Un caso de lo mencionado por Eco, sin ir más lejos, lo podemos encontrar en el mismo Diccionario de la Real Academia de la Lengua Española. En éste, la Antropofagia (del griego $\alpha v \theta \rho \omega \pi \circ \phi \alpha \gamma(\alpha)$ se define como "(...) una costumbre que tienen algunos salvajes de comer carne humana" $\left(1984\right.$, p. 103) ${ }^{2}$. Por otra parte, este mismo diccionario, entiende, en una primera acepción, que Canibalismo es "(...) la antropofagia atribuida a los caníbales" (1992, p. 273) ${ }^{3}$. En otros casos, lo explica también como "Ferocidad o inhumanidad propia de caníbales" (1992, p. 273). Además, específica que Canibal proviene de caríbal y que es el "salvaje de las Antillas, que era tenido por antropófago". En un último sentido, lo califica de la siguiente manera: "Dícese del hombre cruel y feroz" (1992, p. 273).

Estas definiciones están regidas por una mirada parcial, objetiva (eurocéntrica) que, como se puede apreciar, nos permiten concluir que la antropofagia, o más bien, los antropófagos son, para ser literales, "feroces e inhumanos". Conclusión que se ha impuesto en los países que circulan bajo la calificación de occidentales.

Al profundizar esta visión clásica en relación a la antropofagia, uno de los tópicos periféricos que heredó la modernidad fue (y, probablemente, la lectura actual del canibalismo que propone la R.A.E. es una secuela de esto) la "crucifixión" del acto caníbal y su inmersión en lo más recóndito -basándonos en la dicotomía propuesta por Gilbert Durand (1960) en torno a los imaginarios- del régimen nocturno ${ }^{4}$.

2 Real Academia Española. Diccionario de la Lengua Española. Vigésima edición, tomo 1, Madrid, p. 103.

3 Real Academia Española. Diccionario de la Lengua Española. Vigésima primera edición, Madrid, p. 273.

4 Gilbert Durand (1960), indaga, desde un punto de vista fenomenológico, en torno a la creación de símbolos por parte de la mente humana e indica que ésta se divide, por antítesis, entre Régimen Diurno y Régimen Nocturno de la imagen. Por una parte, el régimen diurno se relaciona con la victoria de la luz; en cambio, el nocturno se liga a las valoraciones negativas de esta misma imaginación 
II:

A partir de dicha postura -y por medio, siguiendo a Miquel Rodrigo Alsina, de una semiótica intercultural (Rodrigo Alsina, 2000a)pretendemos recuperar, en un sentido simbólico, ciertas teorías de la antropología, que giran alrededor de la antropofàgia y que nos ayudan a esbozar un proyecto de comunicación interculturál entré:Mismós y Otros. Al respectơ, citámos algunas palabras de Rodrigo Alsina:

Por esto una semiotica intercultural debería no sólo estudiar los discursos de distintas culturas que se entrecruzan e hibridan sino también aquellos discuirsos sobre las culturas y las identidades culturales. (Rodrigo Alsina, 2000, p: 6)

Como se puede desprender de los antes anunciado, nuestra intención es, desde los postulados que construyen actuálmente la antropofagia material (de carne y sangre), proponer una estrategia de antropofagia simbólica que nos permita hacer dèl canibalismo un ejercicio vitäl para los procedimientos hermenéuticos que discuten sobre la existencia o no de límites para la interpretación y que nos son fundamentales para habilitar una estrategia teórica $\mathrm{y}$-esperamos- práctica que otorgue algunas pistas en relación a posibles conjugaciones híbridas entre Mismos y Otros.

Para ello, y a partir de ciertos estudios semióticos, profundizamos sobre la contamináción existente entre diferentes y diversos signos culturales que se van engrosando al alimentarse de ellos mismos permanentemente en un intercambio que relacionamos con la semiosis ilimitada, acuñada por Eco de los trabajos del filósofo y matemático estadounidense Charles S. Peirce: Este ejercicio, para nosotros, faculta la producción de sentidos y ejecuta el libre juego de la interpretación.

diurna: "La valoración' 'negativa de lo negro significaria, según Mohr; pecado, angustia, rebeldia y juicio. En las expresiones del sueño despierto se observa incluso que los paisajes nocturhos son característicos de los estados de depresión" (Durand, 1960, 1981, p. 84). 
Túa Blesa (2002), al referirse a la perspectiva en la obra poética de Jenaro Talens, nos entrega impertantes herramientas para continuar con nuestra propuesta: "(...) el signo puesto en perspectiva dẹl signo, de, manera que no podrá ya ser: concebido como un elemento lingüístico aislado, impensable en sí mismo ${ }_{j}$,sino en perspectiva, en apertura hacia los otros..." (Blesa, 2002, p. 11). Signos que se entregan antropofágicamente (logofágicamenterenipaläbras de Blesa) a los otros, al mismo tiempo, que asimilan la donación que éstos les hacen infinitamente, desvaneciéndose unos en otros en formà indistinta: ,

$\because$. . . . El ritual material de comerse unos a otros, por lo general; era síntoma, dentro de la clasificación antropófaga, de exocanibalismo ${ }^{5}$, ya que el matar y comerse a un enemigo implicaba incrementar el ego personal y grupal de ese conjunto social. El narrador del cuento de Borges "El-informe de Brodie": (1970) se refiere particularmènte a este punto:

- . Devoran los cadáveres crudos de los hechiceros y de los ' ': reyes; 'pàra asimilar su 'virtud. Les eché en cara" ésà costumbre; se tocaron la boca y la barriga, tal vez ṕara $\therefore$ : indicar que los muertos también son alimento o -pero -.....ir esto acaso es demasiádo sutil-para qué yo enteridiera :- :que todo:lo que comemos es, a la larga, carne humana. (Borges, 1970; 1985; p. 375)

Además, como àpunta el comunicólogo brasileño Norvàl Baitello Junior (2000): “(...) en algunas sociedades tribales existía la creencia de que la persona que consumía el cuerpo de otra adquiría las cualidades de ésta, sobretodo si se trataba de un enemigo fuerte, valiente y líder de su tribu". Baịtello Junior es claro al indicar que lo importante para los antropófagos son las imágenes que perciben; que

5 Para W. Arens, el exocanibalismo es el:"(...) canibalismo nitual o mágico, èn que se identifica un intento de absorber la esencia.espiritual del difunto..." (Arens, 1979 , p. 25) C. Vincent, por "su parte, publica ún rëportaje en Le Monde, reduciendo esta clasificación á:: "( $\because$ ) c'est l'éninemi que l'ón dévore, par vénganse, ou pour. s'apropier: ses vertus". (Vincent, 2000, p. 25). 
captan, o que el grupo que conforma la tribu -como receptores interpretantes-aprecia de un cuerpo que se expone en un momento determinado, en el qúe, 'como admiradores del mismo, quisieran tenerlo consigo o ser como él: las imágenes son algo que el cuerpo proyecta. Bajo esta posición, lo sustancial para la antropofágia son las imágenes que el cuerpo produce.

Por lo mismo, la presente situación puede tener un carácter indefinido ya que las tribus se van comiendo unas a otras en forma ilimitada. Todo con la idea de recuperar o incorporaren sí mismos (el devorador o la tribu devoradora), no sólo los atributos que les ofrecen y que, por supuesto, les interesan de sus enemigos; sino también con la intención de rescatar la imagen de su pariente perdido, tiempo atrás, y que fue consumido por ese que él o ellos están dispuestos a comerse en aquel momento. Esta cadena engullidora es un acto de retroalimentación, donde una tribu se come a la otra para recuperar a los suyos y, además, para ganar importantes atributos de éstos que ellos no poseen.

A partir de lo anterior, podemos deducir que los antropófagos no han disociado lo espiritual de lo material y desde un estímulo simbólico, como es la atrayente imagen del otro, se despierta un apetito material que lo lleva, finalmente, a cometer el acto de engullimiento. En síntesis, el caníbal por medio de un ejercicio antropófago simbólico (el comerse la imagen del otro, los signos que el otro produce y que le son atractivos) llega a realizar un acto material como es comerse al elegido para empaparse de las virtudes que éste posee como líder o persona admirable o envidiable de su tribu.

\section{III.}

Para ser más precisos aún, proponemos el siguiente ejemplo que ayuda a comprender empíricamente la semiosis ilimitada y, por ende, lo que nosotros pretendemos denominar, en el campo de lo simbólico, como antropofagia sígnica.

En el cuento de Borges "La escritura del Dios" (1949), el narrador del relato comienza refiriéndose a la situación en la que se encuentra el mago de la incendiada, por Pedro de Alvarado, pirámide 
de Qaholom. Este mago de nombre Tzinacán, describe su experiencia, prisionero en ună profunda cárcel de piedra junto a un jaguar. En la prisión, es sólo separado del felino -ségún él cuenta- por un muro medianéro altísimo que nó alcanza a tocar la parte superior de la bóveda.

En el encierro trata de recordar la sentencia que dios escribió para conjurar los males del fin de los tiempos. Al no poder dar con ella; se acuerda que el jaguar era uno de los atributos del dios. Por lo tanto, dedica múchos años a conocer en detalle al animal que tenía como vecino y que sólo puede observar con el häz de luz que brota cuando el carcelero baja, con una soga, la alimentación una vez al día. En su divagar, Tzinacán saća conclusiones muy provechosas para ejemplificar la antropofagia sígnica como antesala para una semiótica intercultural:

Consideré que aun en los lenguajes. humanos no hay proposición que no implique el universo entero; decir. el tigre es decir los tigres que lo engendraron, los ciervos y tortugas que devoró, el pasto de que se alimentaron los ciervos, la tierra que fue madre del. pasto, el cielo que dio luz a la tierra. Consideré que en el lenguaje de un dios toda la palabra enunciaria esa infinita concatenación de los hechos, y no de un modo implícito, sino explícito, y no de un modo. progresivo, sino inmediato. (Borges, 1949; 2001, p. 137)

Por otra parte, Pierre Menard -el cual no quería componer otro Quijote, sino el Quijote que cada uno de nosotros haleído: el Quijote que surge de todas las posibles y diversas lecturas que se han hecho de éste- no realiza el mismo Quijote que Cervantes, ni un Quijote contemporáneo, sino intenta escribir El Quijote.

En su texto, Menard, que se basa en esta infinitud de lecturas que brotan de la obra cervantina, se "devoró" simbólicamente dicho clásico y sus interpretaciones, llegando a crear un texto aún más perfectò. Es decir los "yoes" que se acercan al texto son una pluralidád de otros textos, de discursos 
y sentidos abiertos. Cada nuevarexpresión desencadena un nuevo ocultamiento. Siguiendo a la académica uruguaya Lisa Block de Behar.(1984), un nuevo silencio que, como sucede con la semiosis ilimitada, nunca detiene este proceso. En la dinámica del silencio también se afirma la semiosis ilimitada del texto: "Nadie es dueñọ de la última palabra, tampoco del último silencio". (Block de Behar, 1984 , p. 190), termina, al respecto, la mencionada autora:

Es así, como las obras de Cervantes y, de Menard son prácticamente idénticas pero, la del segundo de éstos es casi infi-: nitamente más rica: “(Más ambiguo, dirán sus detractores; pero la ambigüedad es una riqueza)", (Borges, 1939, 1956, p. 44), aclara entre paréntesis el narrador de este cuento.

IV.

En la antropofagia sígnica, como fenómeno que insta a la permanente devoración de signos, polemizan; por una parte, sistemas modelizadores y controladores que; al continuar nuevamente con Eco (1990), limitan la interpretación (incluso en su tendencia más radical que este semiótico italiano llama semiosis hermética) y, por otra, una estrategia más deconstructiva, en palabras de Derrida (1967); o rizomática, citando a Deleuze y:Guattari.(1976), que libera totalmente el juego de las interpretaciones a partir de la producción de sentidos.

Desde esta perspectiva pretendemos plantear; a partir del mencionado fenómeno simbólico de antropofagia sígnica, una semiótica que se aproxime a lo intercultural, es decir y como ya lo precisamos, a una semiótica intercultural. Ésta se observa en el momento en que las culturas, de tanto alimentarse reciprocamente entre sí, generan un infinito y diverso mestizaje que se nutre de todas ellas $y$ habilita el surgimiento ya no de un Mismo o de.un Otro, en la dicotomía identidad-alteridad, sino de un "tercero novedoso" que es fruto, de esta contaminación sígnica, como parte de unạ semiosis ilimitada-antropófaga.

En términos teóricos, esto se puede aproximar a lo que. Jacques Derrida (1970) reconoce como un pensamiento del Entre o, 
guardando mínimas diferencias, con lo que Homi Bhabha (1994) llama; a partir de Jameson, tercer espacio (in-between) y cuya labor es aunar, en sus planteamientos, a lo exótico como Otro excluido y a lo. Mismo, ya no desde la tradición occidental, sino desde una différance ${ }^{6}$ que permite movilizar y ampliar la semiosis pàra, así, lograr interculturalizarla.

Este pensamiento del Entre no se caracteriza por una operación de unificación, sino que se entiende como una diferenciación, donde es necesario establecer siempre entre las dos culturas una distinción que produzca a otro nuevo, como resultado de la hibridación de ese Mismo y ese Otro. Tercero(s) que ya no pertenecen, que ya no son del aquí ni del allí. Para esto, se da juego a las más diversas e ilimitadas lineas de fuga (Deleuze y Guattari, 1976) que están dispuestas para anudarse infinitamente entre sí, en un incontrolable y dișlocado ejercicio que relacionamos a este proceso antropófago simbólico.

Nomadismo que se puede identificar, además, con lo que Gilles Deleuze y. Félix Guattari (1976) entienden como movimientos desterritorializados y de desestratificación e indican que todas estas lineas: de fugas constituyen un agencement. Agenciamiento que, permanentemente, esta cambiando su naturaleza, a medida que cada cultura se mezcla y relaciona con otras (y con todàs al mismo tiempo). "Agenciar -nos dice Deleuze- es eso: estar en el medio, en la línea de encuentro de un mundo interior con un mundo exterior" (Deleuze, 1977, pp. 61-62).

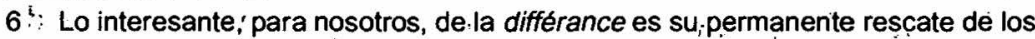
sectores-marginados. Ésta funciona como una estrategia que se va encadenando (antropofágicamente) al igual que un tejido: texto qửe se pródúce en la transformáción de ótro téxto. Para Derrida (1968); la différance es el ejercicio sistemático de las diferencias, de las trazas de las diferencias, del espaciamiento por el que los elementos se relacionan unos con otros, tomando la forma de una intricación, de ún tejido: "(...) de un crucé que dejará partir de nuevo lós diferentes hilos y las distintäs lineas de sentido -o de füerza- igual que estarálista para anudar otras" $(1968,1989$, p $: 40)$. Esto nos permite pensar la relación de los diferentes con la. différance, como una diferencia de la diferencia, que conduce a un desgaste inmejorable dé las categorias de préséncia y de totalización del pensamiento metafísico. 
V.

Dicho esto, y con el propósito (tal vez utópico) de que no se repitan ciertos acontecimientos que buscan sólo una interpretación, sólo un punto de vista, frente a Otras culturas, proponemos retomar, a modo de universales antropológicos, algunos hechos específicos que mencionamos anteriormente en esta comunicación y que, sin duda, colaboraron en la construcción del imaginario transcendental de occidente que hoy tratamos de redibujar.

Para ampliar lo antes expuesto, rescatamos ciertas aportaciones de Sofia Reding Blase (1992) que, basándose en el diario de Cristóbal Colón, refuerzan, en la práctica, las propuestas ya definidas. Imágenes del "nuevo continente" que ayudaron a inventar y deformar representaciones culturales inexistentes. Representaciones fantásticas muy útiles, por otra parte, para el pensamiento eurócéntrico, pues cooperaron en la construcción de una modernidad que, entre otras cuestiones, ofreció a quienes no tenían el honor de conocer las Indias todo una mitología "maligna" y exótica, cuya única posibilidad de aproximarse al bien común era dejarse occidentalizar. Así, estas lejanas y desconocidas culturas se establecieron de nuevo en Europa; describiendo al Otro ausente a partir de una mirada centralista y bajo las exigentes y aniquiladoras normas de la teología de la colonización (Subirats, 2000).

Como consecuencia de lo expuesto, estos actos culturales tienen un valor -en el campo antropófago simbólico-igual de agónico, desde la perspectiva occidental, que los rituales canibales de esos "diferentes" ignorados. Con ello, se revela una suerte de antropofagia simbólica colonizadora en la que caen los conquistadores. Involución que se pone de manifiesto en las huellas del desastre, de la aniquilación del Otró a través de esta antropofagia simbólica que retrocede a etapas prehomínidos para alimentarse salvajemente de Otros "salvajes", calificados de "no hombres" por su locación fuera del limitado y cerrado universo occidental que aboga, en palabras de Foucault (1966), por la estabilidad y permanencia de las ciencias humanas. 
Jean Baudrillard (1995) - cuando se refiere a la supresión del Otro bajo todas sus formas, sin considerar las diferencias de raza y lengua - precisa que, al tratar de anularlos para hacer relucir la positividad total, están a un paso de eliminarse ellos mismos. Mismos que fueron y son víctima de un acto de autoengullimiento, de autoantropofagia simbólica, donde el asesino y la víctima son una misma persona. Reding. Blase (1992), al respecto, indica que al destruir, en el adversario, la inhumanidad del contra-hombre no se puede, sino, más que destruir la humanidad del hombre y realizar en él su propia inhumanidad.

De esta (auto)antropofagia simbólica quedan huellas imborrables, resultado - como lo expone Baudrillard - de un crimen perfecto (1995) que les llevó a descubrir que su "canibalización" consintió en comerse a una cultura diferente: se comieron a esos Otros como a sí Mismos.

Para finalizar, nos parece oportuno recordar una particular escritura que, tras "devorarse" simbólicamente el Manifiesto Antropófago, propone Eduardo Subirats (2000):

Por eso el Manifesto Antropófago avisa: 'lo que atropellaba la verdad era la ropa'. Desnudar la palabra, emanciparla de su servidumbre logocéntrica y cristiana. La palabra devuelta al último Paraíso. Poesía final. (Subirats, 2000, p. 91)

\section{Bibliografía}

ANDRADE, O. de. 1928. Manifesto antropofago. Revista de:Antropofagia, 1, Sao Paulo, p. 3 y 7.

ARENS, W. 1981. El mito del canibalismo: antropología y antropofagia. México: Siglo XXI.

BAITELLO JUNIOR, N. 2000. Conferencias impartidas en la Asignatura "El tiempo y él espacio en la comunicación" del Programa de Doctorado "Proceso de la comunicación", 19-20 
de enero, Sala Mixta, Departamento de Comunicación Audiovisual, Publicidad y Literatura, Universidad de Sevilla.

BAUDRILLARD, J. 1996. El crimen perfecto. Barcelona: Anagrama.

BHABHA, H. 1994. The location of culture. London: London/ New York.

BLESA, T.2002. En perspectiva (Una lectura de la poesía de Jenaro Talens). Conferencia pronunciada en el II' Seminario "Poesía hispánica desde el siglo XXI: Jenaro Talens: la escritura de Orfeo", 14 de mayo, Depártamento de Comunicación Audiovisual, Publicidad y Literatura, Universidad de Sevilla.

BLOCK DE BEHAR, L. 1994. Una retórica del silencio: funciones del lector y prócedimientos de la lectura literaria. México: Siglo XXI.

BORGES, J.L. 1956. Ficciónes. Buenos Aires: Emecé.

LA ESCRITURA DEL DIOS. 2001. El Aleph, Madrid: Alianza, pp. 133-141.

EL INFORME BRODIE. Jorge Luis Borges. Diccionario: una antología de sus textos. Edición, introducción, prólogos y notas de Emir Rodríguez Monegal. México: F.C.E., 1985, pp. 374-379, 1970.

DELEUZE, G. 1996. Conversaciones. Valencia: Pre-textos.

y GUATTARI, F. 1997. Rizoma (introducción) Valencia: Pre-textos:

DERRIDA, J. 1971. De la gramatología: Buenos Aires: Siglo XXI.

(1968): "La farmacia de Platón" publicado originalmente en Tel Quel. La diseminación (1972). Madrid: Fundamentos, 1975.

(1970): La doble sesión. Publicado originalmente en Tel:Quel. La diseminación (1972). Madrid: Fundamentos, 1975.

DURAND, G. 1981. Las estructuras antropológicas de lo imaginario.: introducción a la arquetipología general. Madrid: Taurus.

ECO, H. 2000. La fuerza de la cultura podrá evitar el choque de civilizaciones. Discurso pronunciado en Jerusalén con motivo del doctorado honoris causa concedido por la Universidad Hebrea. El País, Opinión, 12 de junio, Madrid, p. $11-12$. 
FOUCAULT, M. 1996. Las palabras y las cosas. México: Siglo XXI.

PEIRCE, C. S. 1987. Obra lógico semiótica. Madrid: Taurus.

REDING BLASE, S. 1992. El buen salvaje y el caníbal. México: U.A.M.

RODRIGO ALSINA, M. 1999. Comunicación intercultural. Barcelona: Anthropos.

SUBIRATS, E. 2000. Antropofagia contra globalización o el Paraíso en América Latina. Quimera, 193-194, Barcelona, p. 88-91.

VILLALTA, B. 1970. Ritos caníbales en América. Buenos Aires: Casa Pardo.

VINCENT, C. 2000. L'homme a mangé de l'homme: la preuve par la myoglobine chez les Anasazi. Le Monde, 8 de agosto, Paris, p. 25. 